\title{
UNA CASUALIDAD CONTROLADA: LA PRIMERA VIDA POSMODERNA
}

\author{
Daniel N. Jiménez Ferrera \\ Doctor Arquitecto y Professor de Proyectos Arquitectónicos, Escola de Artes. \\ Universidad de Évora, Portugal \\ https://dx.doi.org/10.12795/astragalo.2017.i23.09
}

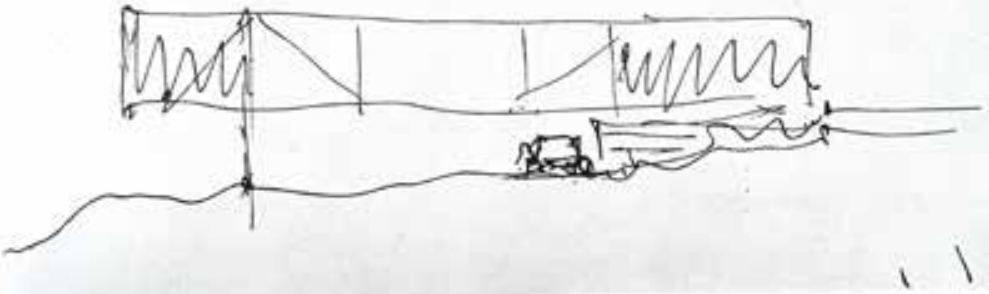

Mies van der Rohe, la casa de cristal en la ladera, tal como aparece en el catálogo de la exposición de 1947 del MoMA de Nueva York, p. 109.

Como no pocos proyectos, el origen de este texto es fruto de una casualidad. Hace unos años me topé en Londres, en la librería Walden Books del 38 de Harmood St., con una primera edición de la conocida monografía de Mies a cargo de Philip Johnson. El librito, en realidad catálogo de la exposición que en 1947 el MoMA de Nueva York dedicara a la obra de Mies Van der Rohe a los diez años del desembarco del arquitecto en Estados Unidos, tiene un tamaño de 10 x 7,5 pulgadas, es decir, la mitad del formato americano Crown (20x15 pulgadas), equivalente a 508 x $381 \mathrm{~mm}$. Se imprimieron, en su primera tirada, editada por The Plantin Press, 12.000 ejemplares. Ese mismo año, con edición al cuidado de Reynal y Hitchcock, se publicaría la primera traducción al inglés de Cuando las catedrales eran blancas de Le Corbusier y una selección de poemas de Lorca, siete años después de su Poeta en Nueva York. En la monografía, en la página 109, aparece el conocido croquis de Mies Sketch for a glass house on a hillside. c. 1934, escasamente unas líneas, aunque precisas y llenas de matices, de la casa en una ladera que rápidamente nos remite a aquella primera propuesta de Saarinen para una casa en el aire, primero en 1941 en Pensilvania y después, en 1945, con Charles Eames, en Los Angeles, que nunca llegarían a construirse, sino en su aliteraciones posteriores realizadas por Harry Seidler (Julian Rose House, Wahroonga, Sydney, 1949), Philip Johnson (Leonhardt house, Long Island, Nueva York, 1956) o Craig Ellwood (Smith House, Crestwood Hills, 1958; Frank \& Polly Pierson House, Malibú, 1962; Chamorro House, Hollywood Hills, 1963, o la serie Weekend House, con Gerald Horn, entre 1964 y 1970, hasta el magnífico Art Center College of Design de Pasadera, su puente habitado de 1977). El relato que da origen al texto discurre en un estricto 
período de tiempo, desde los primeros dibujos de la Case Study House $n^{\circ} 8$, dentro del programa promovido por John Entenza y su revista Arts \& Architecture en California, realizados en el estudio de Saarinen en Bloomfield Hills, Michigan, hasta que el proyecto de la casa Eames finaliza cinco años después de acabar la obra en 1955, en la versión conocida, radicalmente distinta al proyecto original, cuando la pareja Charles y Ray Eames edita el corto House After Five Years of Living. La discusión original en torno a esta casita, o mejor, a las circunstancias, casualidades controladas, que rodean su construcción, se establece estrictamente cuando rastreamos aquellos invariantes que se mantienen en las dos versiones y las reconcilian. En este corto período de tiempo se producen en el proyecto una serie de decisiones que permiten descubrir, tanto en la forma como en el mismo proceso transformador del proyecto, en su obsesivo registro, en los nuevos referentes asumidos y propuestos, la primera visibilidad del cambio del paradigma moderno.

Eames. 203 de Chautauqua Boulevard, Pacific Palisades, Los Ángeles, California, USA. Enero de 1945 - diciembre de 1949 (hasta 1955).

En el verano de 1944 Charles Eames y Eero Saarinen reciben el encargo de la revista Arts \& Architecture y en particular de su editor, John Entenza, de construir, dentro del programa Case Study Houses, las casas números 8 y 9 de una serie de treinta y seis viviendas unifamiliares y dos edificios de apartamentos. De acuerdo al anuncio publicado en el número de enero de 1945 de la revista, las casas proyectadas deberían responder al objetivo de crear una casa capaz de ser repetida en el sentido de no asumirse como una puesta en escena individual, dando una buena solución a cada problema (lugar, programa, presupuesto...) pero sin perder el carácter tipológico que permitiese generalizar el modelo, para, de una manera pragmática, atender las necesidades del americano medio y su búsqueda del sueño nacional de una casa en la que pueda permitirse vivir ${ }^{1}$.

Después de la Segunda Guerra Mundial la gran mayoría de periódicos y revistas generalistas se llenaron de anuncios con las nuevas viviendas que esperaban a los combatientes a su regreso. Muchos de ellos usaban el imaginario convencional de un acogedor hogar tradicional, pero para muchos otros medios era el momento de plantear alternativas, siquiera apenas formales, al arquetipo de casa. En 1945 la revista House \& Garden, que ya en su número de febrero de 1944 publicaba la casa Weston Havens de Harwell Harris ${ }^{2}$ con fotografías de Man Ray, describiría la arquitectura moderna como una lucha continua en la conquista de la libertad $\mathrm{y}$, apenas unas líneas después, sentenciaba con un dramático si los soldados tienen que regresar a las casas anticuadas y los cuartos oscuros que los vieron partir, podremos dar la batalla por perdida. En el mismo sentido, House Beautiful encargará a Cliff May el proyecto de la House Beautiful Demonstration House, un trasunto de rancho moderno calificado por la revista como the house to which Johnny dreams of marching home to (...) one

1 ENTENZA, John: Announcement: The Case Study House Program, Arts \& Architecture, enero de 1945, p. 39, traducción del autor.

2 Además de las publicaciones en California Arts \& Architecture y House \& Garden, la Weston Havens House aparecería, fotografiada por Man Ray, en Life Magazine, House Beautiful, Architectural Record, Architectural Forum, AIA Journal, Magazine of Art, American Builder, Architectural Design, House \& Home, Revista de Arquitectura, Nuestra Arquitectura, Byggmastaren, Studio, Pageant o Household, entre otras. 
of the ideals these veterans have fought for and which they can now look forward to attaining. No sólo había cinco años de demanda acumulada, a los años de la guerra había que sumar los de la Gran Depresión, por lo que casi quince años de carestía ofrecía un mercado ávido de gastar el dinero que empezaba a fluir y con ganas de hacer algo distinto a sus padres.

Así, Entenza, en la estela de las publicaciones de la costa este, pero también consciente de las experiencias europeas de la Werkbund de los años treinta, y aún más atrás, desde las ciudades ideales renacentistas, barrocas e iluministas, hasta las grandes ferias internacionales del siglo XIX donde comenzaban a mostrarse al creciente público consumista los adelantos tecnológicos y espaciales en el ámbito doméstico, pensó en construir casas que colaborasen a la venta de su revista. Casas que proporcionasen para ser exhibidas nuevas y brillantes imágenes sin restricciones, casas para ser equipadas y vendidas, más cercanas a las pre-cast houses de Irving Gill en California en la primera década de 1900 o a los escarceos comerciales de Frank Lloyd Wright y sus diferentes negocios con Sherman Booth en Glencoe, las Ravine Bluffs Houses de 1915, o para los Richards Brothers y su American Ready-Cut System entre 1916 y 1918 que a sus remedos europeos, All-AmericanMade, pero, sobre todo, casas cuyos nuevos espacios el público pudiese experimentar:

...houses that the public could walk in and see... ${ }^{3}$

Ese mismo año crucial, 1945, Entenza anunciaría en el primer número del año, el Case Study Program.

3 MCCOY, Esther (memoria oral, U.C. Berkeley): Case Study House Lecture, U.C. Santa Cruz, 2 de mayo 1978

\begin{abstract}
What man has learned about himself in the last five years will, we are sure, express itself in the way he will want to be housed in the future. Only one thing will stop the realization of that wish and that is the tenacity with man clings to old forms because he does not yet understand the new. ${ }^{4}$
\end{abstract}

Y toma conciencia, clarividente, en la íntima conexión entre el cambio real que se estaba produciendo en la arquitectura, los cambios éticos, incontrolables, inexorables, inevitables y los complejos estéticos y formales resilientes, que, sin embargo, podían controlarse, suavizarse y moldearse, evitando así que su banal enquistamiento provocase el rechazo inmeditado a los primeros. Necesitaba un modelo de casa que no militara, como lo habían hecho las Model Houses vinculadas al American-way-of-life, en la imposición de un estilo de vida, sino un hogar que sirviera tanto de escenario como de infraestructura para permitir al habitante desarrollar una vida propia, elegida o imaginada. Unas casas posibles a la vez que propositivas. Experiencias previas de casas modelo o study houses como la Dymaxion House de Fuller en 1927 o la Aluminaire House del antiguo colaborador de Le Corbusier, el suizo Albert Frey, con el arquitecto americano A. Lawrence Kocher, editor de Architectural Record, heredera metalúrgica de la maison citrohan ${ }^{5}$, presentada en la Architectu-

\footnotetext{
4 ENTENZA, John: Announcement: The Case Study House Program, Arts \& Architecture, enero de 1945, p. 39

5 La Tin House, como se la denominó irónicamente, contaba con unos $110 \mathrm{~m}^{2}$ distribuidos en tres niveles, soportados por seis pilares de sección circular de $13 \mathrm{~cm}$ de diámetro, con fachadas de panel de aluminio acanalado sobre tablero
} 
ral and Allied Arts Exposition de Nueva York en $1931^{6}$, no dejan de ser objet trouvés, atracciones circenses y crecepelos milagrosos.

\begin{abstract}
After working with Le Corbusier in Paris, my aim in life was to use permanent materials that don't require maintenance. Aluminum was an up-and-coming material, much more durable than wood, or plaster, which cracks. And it went up very quickly. The house was built in 10 days. $^{7}$
\end{abstract}

En Chicago, la A Century of Progress Exhibition, organizada en 1933 para celebrar el centenario de la ciudad con el lema Science Finds, Industry Applies, Man Conforms y emparentada astralmente con la Exposición Colombina de $1893^{8}$,

aislante, remachados a la subestructura de perfiles omega y con acabado interior en tela. Los forjados se realizaron en chapa de acero prensado, acabados en linóleo de color negro. La iluminación en neón ocupaba un foseado perimétrico del techo, los baños contaban con ventilación forzada, las camas estaban suspendidas del techo y la puerta del garaje se abría mediante célula fotoeléctrica que se activaba con una ráfaga de las luces del coche.

6 WEBB, Michael: Modernism Reborn: Mid-Century American Houses, Rizzoli International Publications, Nueva York, 2001, p. 58

7 Una feria celebrada en el Grand Central Palace de Lexington Avenue en la que la medalla de honor recayó en el Empire State Building. La casa de Frey, levantada apenas en diez días, recibe la visita de más de 100.000 personas la primera semana del evento. Entrevista a Albert Frey en The New York Times, 1998, unos meses antes de su muerte en Palm Springs, California, el 14 de noviembre de ese mismo año.

8 En la ceremonia de inauguración la iluminación eléctrica de la Feria se encendió tras la activación de una célula fotoeléctrica tras recibir la luz de la estrella Arturo (Alfa Bootis, las más brillante del hemisferio norte), situada a casi cuarenta años luz de la Tierra y, por tanto, iluminando el cielo de 1933 con la luz de 1893, el año de la celebración de la Feria Colombina. presentará una sección, Houses of Tomorrow, donde un grupo de arquitectos e industriales reciben el encargo de diseñar prototipos residenciales que conceptualicen las formas en las que la nuevas tecnologías puedan cambiar la industria de la casa, especialmente en el tema de la prefabricación (a handful of architects and manufacturers was charged with designing housing prototypes that would conceptualize ways in which new technologies could change the housing industry, particularly of the prefabricated varie$\left.t y^{9}\right)$. Construirán nueve casas, prototipos residenciales a escala real, presentados en el Home Planning Hall: The House of Tomorrow, The Florida Tropical House, The Cape Cod Cottage, The Common Brick House, The Wiebolt-Rostone House, The Lumber Industries House, The Masonite House, The Armco-Ferro Enamel House y The Cypress Log House, todas visitables, aunque distribuidas de una manera bastante artificial, como maquetas gigantes, en el área urbanizada para la feria a lo largo del Burnham Park, al sur del downtown, entre la avenida Lake Shore Drive y el lago Michigan. Los proyectos de mayor interés serían la House of Tomorrow (1933) y la Crystal House (construida para la reapertura de la Feria en 1934) de George Fred Keck, que había participado en la exposición del Estilo Internacional de Hitchcock y Johnson en el MoMA un año antes.

The most audacious of the houses, all built at full scale, was George Fred Keck's Crystal House. Equipped with a four-point manifesto, Keck defines not only a formal typology but also many architec-

9 BERGDOLL, Barry, CHRISTENSEN, Peter y BROADHURST, Ron (editores): Home Delivery: Fabricating the Modern Dwelling, The Museum of Modern Art, Nueva York, 2008 
tural issues that were completely new. The first point discusses the open plan in relation to cost effectiveness; the second references the house as the servicer to its inhabitant, not vice-versa; the third focuses on the importance to one's health of passive heating and the modulation of natural light; the final point outlines the need to design within the boundaries of mass production without relinquishing the "opportunity for individual expression" tastefully and affordably. ${ }^{10}$

En 1936 Los Angeles Building Center y Marie Louise Schmidt, directora de la Architectural Building Material Exhibit, encargarán a Richard Neutra la Plywood Model Demonstration House, único de los seis prototipos de menos de $\$ 5.000$ de coste, con proyecto moderno. Neutra proyectó la casa, que sirvió de modelo para el debut en la fotografía de arquitectura de Julius Shulman, publicada en el número de julio de 1936 de Architectural Forum, para la California House and Garden Exhibition celebrada en el 5900 Wilshire Blvd. en el Miracle Mile district donde hoy se elevan los 33 pisos del Mutual Benefit Plaza Complex de William L. Pereira. Las seis casas se sortearon resultando ganadora de la de Neutra Stella Gramer, la socia abogada del padre de Entenza, que poseía una parcela en el 427 de Beloit Avenue en Brentwood Glen, donde trasladaron la Plywood Model Demonstration House que aún sigue allí.

10 BERGDOLL, Barry, CHRISTENSEN, Peter y BROADHURST, Ron (editores): Home Delivery: Fabricating the Modern Dwelling, op. cit.
Frente a las casas de Fuller, Frey o Keck, la casa de Neutra, con su evidente precedente en la casa que proyectara para Werkbundsiedlung de Viena de 1931, tuvo bastante éxito, y no solo en California, donde Neutra ya gozaba de bastante popularidad, sino especialmente en Nueva York, donde se exhibiría una maqueta de la casa, realizada por Stanton B. Coffin para la exposición del MoMA de 1939 Art in Our Time, que celebraba el décimo aniversario del museo, así como su traslado al nuevo edificio en el 11W de la calle 53, y que sería cabecera simultánea de los artículos sobre la muestra en The New York Times y Los Angeles Times el 21 de mayo de 1939. Con estos precedentes, los concursos desarrollados por Arts and Architecture con anterioridad al programa Case Study, Small Houses, Postwar Living, Postwar worker, sirvieron para tantear las alternativas, formales y constructivas, que Entenza intuía para la oferta de este nuevo habitar: prefabricación, asociada tanto a la rapidez y abaratamiento de costes demandados en el cambio de paradigma del mundo y de la casa, como a la industria disponible y, por tanto, al desarrollo económico y a las plusvalías generadas; equipamiento, ligado al nuevo concepto de lujo y de confort; naturaleza, favoreciendo que la casa participe de su entorno natural o lo recree, lo naturartificial, desligándola de la ciudad como hecho exclusivamente artificial y entendiendo este contacto tanto por su relación con la arquitectura sostenible, anticipándose a Víctor Olgyay y su arquitectura bioclimática ${ }^{11}$, como con la idea, pintoresca y

11 OLGYAY, Víctor: Design with climate. Bioclimatic approach to architectural regionalism, Princeton University Press, 1963. Víctor y su hermano gemelo Aladar volverán a los pueblos mexicanos que ya fascinaran a Schindler, parametrizando sus sombras, sus densidades y sus espacios intermedios... 
fenomenológica, del hortus conclusus; imagen, la casa se convierte en proyección del que la habita más que en el refugio íntimo del guerrero, la actividad social, ya de ambos cónyuges en la pareja o del soltero activo, que invita a pensar el espacio de la casa como una extensión del espacio público.

El salto mortal de la sociedad norteamericana, desde aquella Exposición Colombina de 1893 que hiciera regresar a Adolf Loos a Europa con los ojos llenos de vacío, provocaba vértigo. El país se había hecho adulto sin pasar por la adolescencia. En 1900 más de la mitad de la población de Estados Unidos, con 76 millones de habitantes en el comienzo del siglo, vivía en zonas rurales, dependía de una economía agrícola basada en el modelo granjero de las explotaciones familiares, sufría tasas de analfabetismo de más del 20\% entre los blancos y casi del 50\% entre los negros y sólo funcionaban en el país 600.000 líneas de teléfono. Apenas medio siglo después, en la década de 1950, el modelo había cambiado: la mitad de los estadounidenses vivía en ciudades, la misma proporción residía en casas en propiedad, la escolaridad era casi universal y había 50 millones de aparatos telefónicos. También el arte estaba cambiando desde la herencia europea de la primera década del siglo.

En este contexto se inicia el programa Case Study House de John Entenza y Arts \& Architecture. Y la casa CSH\#8. En su proceso de construcción es habitualmente aceptado que desde el encargo y la publicación propagandística del programa, así como el primer proyecto de Eames-Saarinen dibujado en ese verano en el estudio de Eliel en Ann Arbor, hasta la primera nochebuena, la de 1949, que los Eames pasan ya en su casa, el proyecto de estructura de acero y cerramiento ligero de paneles ferroboard sufri- rá la carestía del metal en la recién estrenada postguerra y ese retraso, tiempo de viaje, tendrá las conocidas consecuencias de su mutación espacial y formal, ya de la mano de los Eames. Diversos autores, desde Esther McCoy a Beatriz Colomina, pero también John Crosse, Gloria Koening, David Travers o Peter Yates han atribuido el cambio del proyecto de la CSH\#8 a un deseo de individualismo, de originalidad, de Charles Eames ante la evidente cercanía de su proyecto al conocido boceto de Mies, dibujado en 1934, la Glass House on a hillside, que Charles Eames vería en la exposición monográfica Mies van der Rohe organizada por Philip Johnson y celebrada en el MoMA de Nueva York en 1947, a los diez años de la llegada de éste a los Estados Unidos. Aunque ninguno de los citados recuerda, amnesia táctica, el proyecto de Saarinen de 1941, la casa Samuel Bell en New Hope, Pennsilvania, que ya proponía una casa en voladizo, incrustada en una ladera, precedente de la CSH\#8, como ignoran todos los puentes habitados, previos y futuros, que pertenecen a la familia del proyecto de Mies. El origen del cambio es otro.

El proyecto original de Eames+Saarinen necesitaba ser un puente porque perciben como separados la casa y el prado que la recibe. Son modernos, una joven idea. Joven, por ser jóvenes. Joven, por ser temprana: idea de Mies, o de Eames, o de Saarinen. Y así, pues, diseñan una escalera, como la que ya existía en la maqueta del proyecto de Saarinen en New Hope y que Mies escamotea en uno de sus zócalos habitables en el croquis de 1931, una escalera para ascender desde la desordenada naturaleza de Los Ángeles y de Pacific Palisades, incluso del programa Case Study Houses, que, sin urbanidad, 

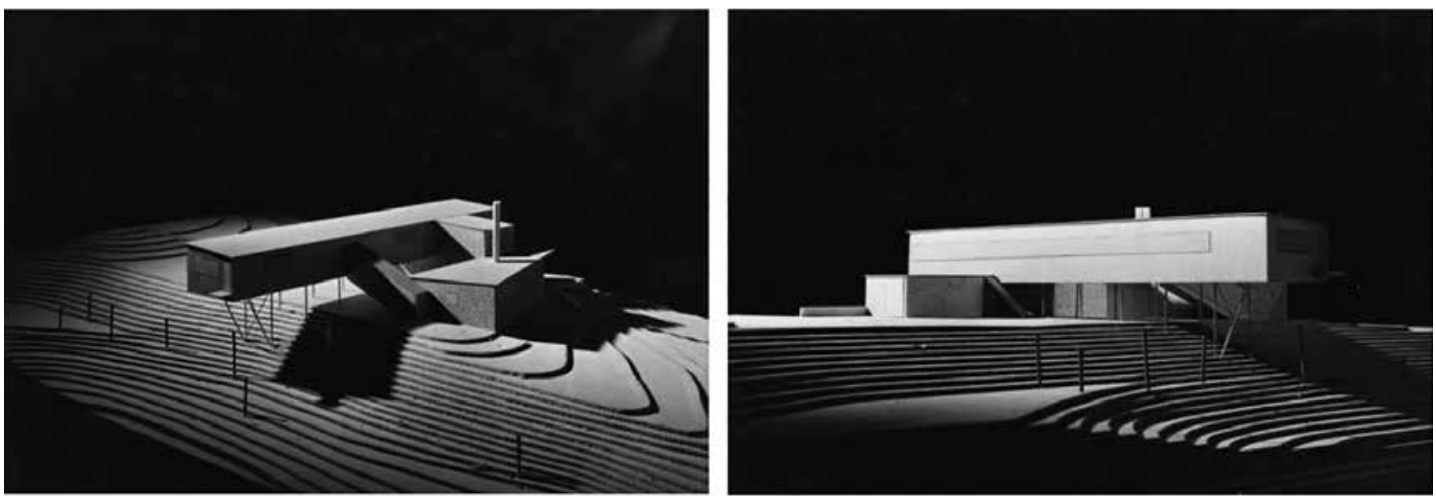

Eero Saarinen, proyecto para la casa Samuel Bell, heredero de Genral Mills, en New Hope, Pennsilvania, julio 1941. Pictures, Library of Congress, Washington.
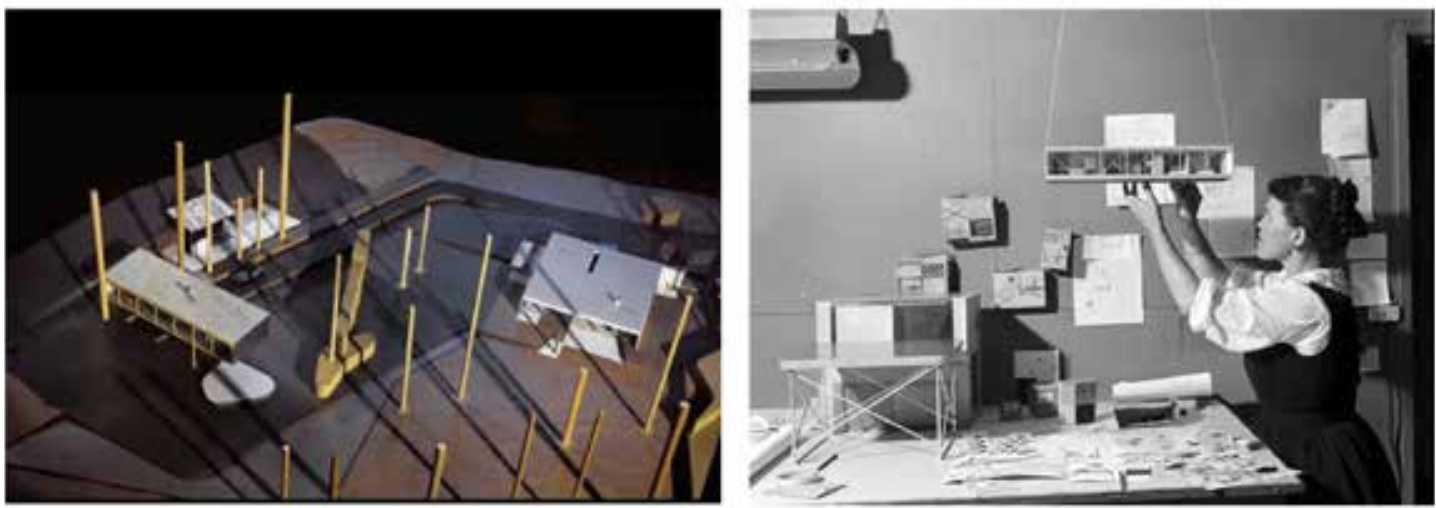

La CSH\#8 con su estructura amarilla. Eames office, Los Angeles // Ray Kaiser Eames, pintando la maqueta de la CSH\#8. Los Angeles, circa 1948. Fotografía de Peter Stackpole

para LIFE. Eames office, Los Angeles.

salpicaba la ciudad de bellos objetos pugnando por relacionarse, hasta el organizado sosiego de la casa. Ésta, aún elevada, ligera, puente, y por tanto paso, presenta incongruente uno de esos ingelnooks que se excavan en el terreno de las confortables casas nórdicas, aprovechando, como una madriguera moderna, su inercia y su acomodo. Todo era artificial, todo era moderno. Como reclama el programa de Entenza. Pero el tiempo que pasa con la obra sin comenzar permite a los Eames habitar el prado, enseñarlo, usarlo, vivirlo. Ray sólo quiere un umbral. Man- tener el prado porque nunca lo vio desligado de su futuro hogar. No son dos elementos que unir, la casa ya existía antes de ser construida. Las fotografías, obsesivas, que Charles toma en cada visita del lugar donde vivirán, inventario incansable, lo demuestran. No son imágenes del solar a ocupar. No son, más tarde, un registro de la obra; ni son, cinco años después de aquellas navidades de 1949, un registro de la vida. Constatan que el espacio colonizado por los Eames siempre estuvo allí. Ellos se limitaron a construir un umbral, un umbral sin puerta, 
como los de Duchamp primero y los Smithson más tarde. Un lugar donde la respiración se detiene un instante para exhalar el aire en otro sitio, el mismo aire, el mismo sitio.

Esa escalera que Ray nunca incluirá en la maqueta será el desencadenante del cambio del proyecto. Parece escucharse de fondo a Bachelard, la escalera que sube a un desván siempre sube y nunca baja, igual que siempre baja y nunca sube la de un sótano. Una casa que nunca tuvo puerta, que nunca se unió al lugar, incluso años más tarde de construirse su versión definitiva. Los restos de la maqueta de la estructura amarilla permanecen en el estudio de Santa Mónica algunos años, colgados de finos sedales del techo, flotando, separada ya de su único apoyo en la ladera, un puente que ni Wright, ni Le Corbusier, pero tampoco Mies o Eames se atreverían a construir, un puente sin apoyos.

Recordar es volver, cualquier recuerdo supone haber vivido, haber participado de las cosas que encontramos cuando no éramos lo que somos. Recordar es también trasladar nuestro momento de ahora, vivirlo de otra forma, desdeñar un poco nuestro presente y permitir que el pasado lo ocupe casi todo, interrumpir conscientemente nuestro camino hacia adelante ${ }^{12}$.

Charles no quiere recordar. Sí seguir adelante. Dice Borges que el olvido es la mejor forma de la memoria, además de la de la anulación de lo horrible o lo indeseable, otra de las bondades del olvido es la posibilidad que da al hombre de ejercer su imaginación reinventando lo sucedido: modificar el pasado no es modificar un solo hecho; es anular sus consecuencias, que tienden a ser infinitas. Dicho sea con otras palabras; es

12 LABORDA YNEVA, José: Roma, ciudad y tiempo, colección Estudios de Arquitectura, Institución Fernando el Católico, Diputación de Zaragoza, Zaragoza, 2005 crear dos historias universales ${ }^{13}$. Los Eames han encontrado su rincón del universo, choose your corner, pick away at it carefully, intensely and the best of your ability and that way you might change the world ${ }^{14}, \mathrm{y}$, de repente, todo encaja: eventually everything connects - people, ideas, objects... the quality of the connections is the key to quality per $s e^{15}$.

Si comparamos el estado final de la Case Study Houses \#8 y \#9 con el proyecto inicial de Charles Eames con Eero Saaarinen y Edgardo Contini (el encargado de diseñar la estructura, que también trabajara con Harris, con Soriano y con Quincy Jones) podemos verificar que en la casa de Entenza apenas se produce ninguna alteración en los cuatro años de espera entre la redacción del proyecto y su puesta en obra, mientras que en la casa Eames, además de las diferencias obvias de ocupación del solar o la estrategia formal, la aliteración miesiana, de la casa-puente prevista inicialmente, el proyecto compartido con Saarinen, y prácticamente desarrollado por éste en exclusiva, las divergencias entre ambas versiones ejemplifican el tránsito de la modernidad hasta la postmodernidad, en un inicio del hecho contemporáneo algo más pacífico, y temprano, que el hito elegi-

13 La reflexión sobre el olvido creativo y regenerador es el tema de otro de los cuentos de Borges, La otra muerte, en el que el personaje principal, el coronel Tabares, olvida la muerte de don Pedro Damián, que se produce por su extrema cobardía, reinventando en su memoria una muerte heroica para él. BORGES, Jorge Luis: El Aleph, El Libro de Bolsillo, Biblioteca de Autor, Biblioteca Borges, Alianza, Madrid, 1999

14 AA Files: Annals of the Architectural Association School of Architecture, $\mathrm{n}^{\circ}$ 31-32, 1996, p. 111

15 BIZIOS, Georgia: Architecture Reading Lists and Course Outlines, Eno River Press, Durhan, N.C., 1998, p. 494 


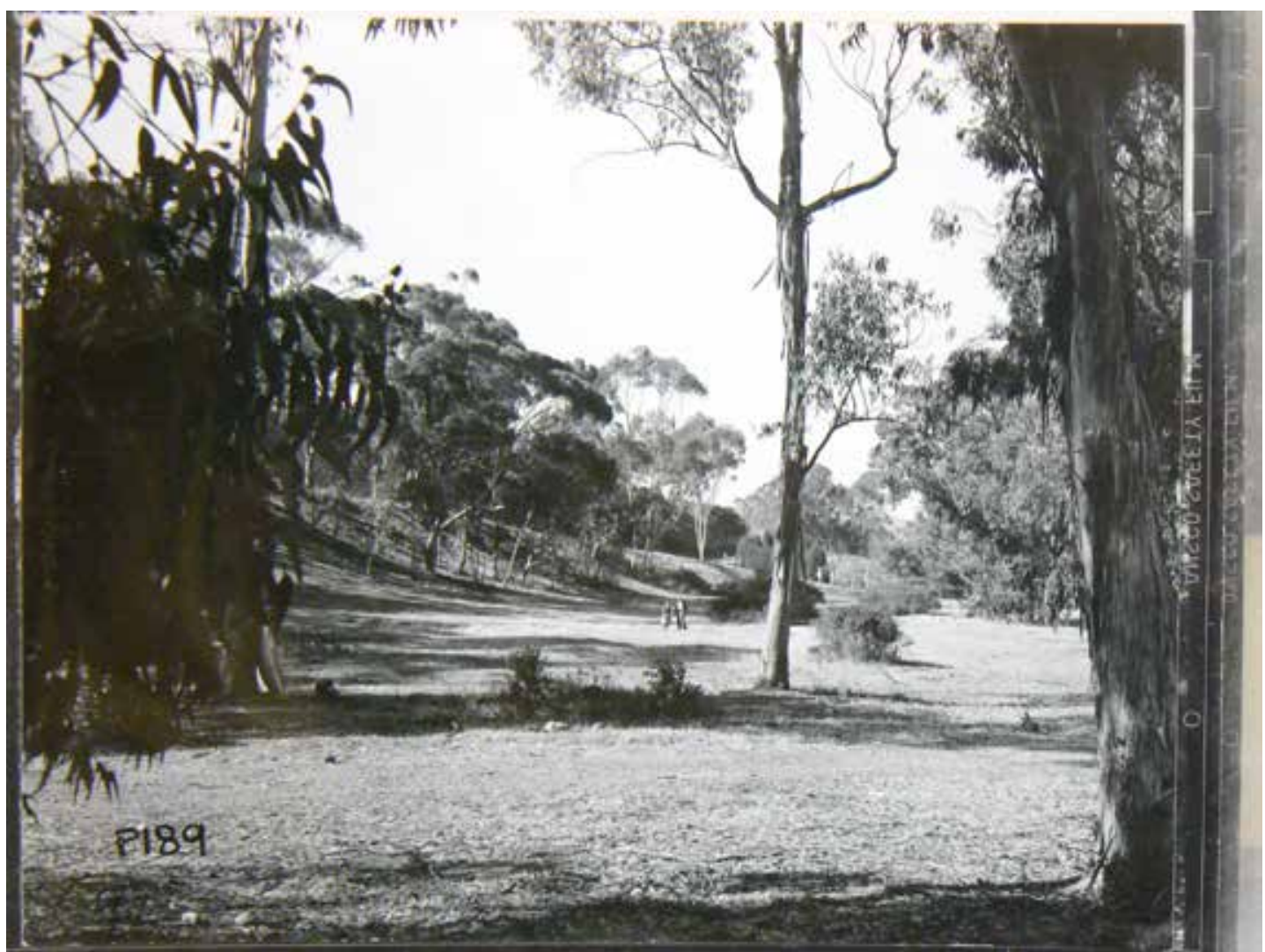

The meadow. Ray Eames con John Entenza en Chautauqua, 15 de septiembre de 1946, fotografía de Charles Eames. Eames papers, Library of Congress, Washington.

do por Charles Jencks, para el que el posmodernismo comienza con la demolición de los treinta y tres bloques residenciales Pruitt-Igoe en Saint Louis, Missouri, del arquitecto del World Trade Center de New York, Minoru Yamasaki, el 15 de julio de 1972.

Jencks analiza la nueva dirección tomada por la arquitectura tardomoderna desde su relación con la metáfora, cuantas más metáforas despierte una arquitectura, tanto mayor será el dramatismo; sin embargo, cuanto más sean esas metáforas meras insinuaciones, tanto mayor será la incertidumbre semiótica ${ }^{16}$, y remite a la diferenciación de Robert Venturi entre lo literal (el pato, signo iconográfico) y lo formal del edificio (la caja decorada, el signo simbólico). Si su posmodernidad no es sino la arquitectura que vino del lenguaje, la arquitectura del intercambio, o mejor del recambio, de la polisemia, del esto y lo

16 JENCKS, Charles A.: The Language of Post-Modern Architecture, Academy Editions, New York, 1977, en su versión en castellano, El lenguaje de la arquitectura posmodema, editorial Gustavo Gili, Barcelona, 1980 

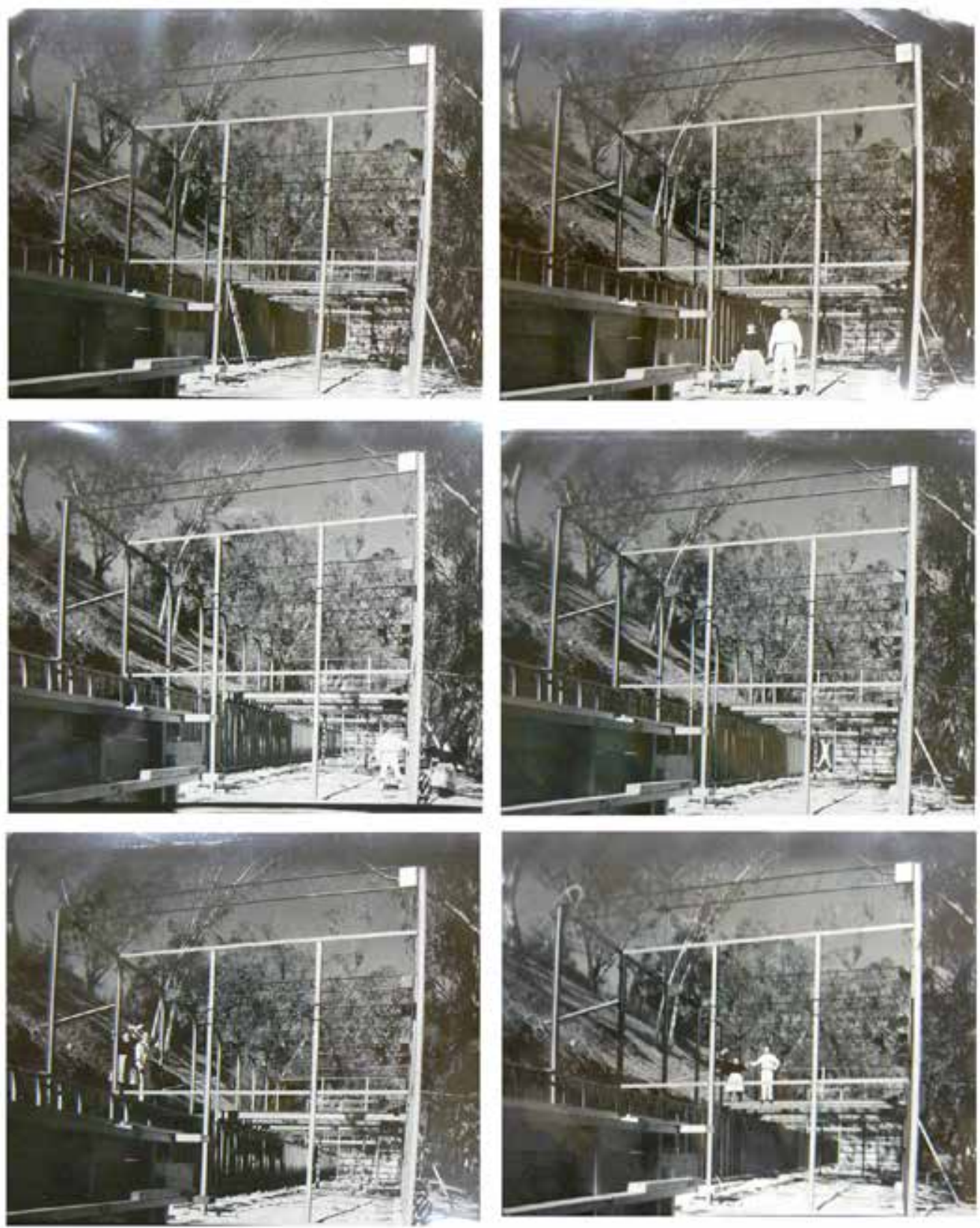

30 de diciembre de 1948. Eames papers, Library of Congress, Washington. 
otro antes que de $o$ esto o lo otro ${ }^{17}$, la casa Eames permite la primera visibilidad de este cambio del paradigma moderno, en el que todo es posible, y a la vez. Cambio que se produce, una de estas casualidades controladas, tanto de manera literal como sensible. Por un lado, la migración del proyecto desde su formalización canónicamente moderna (la relación con el terreno, su trasparencia, la pregnante estructura) hasta la definitivamente ejecutada; por otro, el viaje interior de los Eames, sus obsesivas imágenes, registros construidos desde la avidez de la mirada de arquitecto, así como el trabajo continuo sobre la propia obra, sólo terminada cinco años después de su conclusión.

Una obra en la que los límites son difusos pero estrictos: los reflejos en la exacta trama de Los Eames proponen una arquitectura más allá del acomodo feliz de los objetos que definen su particular estilo de vida. Un proyecto construido como un proceso de acercamiento a la casa, reflexionados, encontrados, sus recorrido, umbral y recinto. Una suerte de catarsis que culmina en la nueva idea de casa como un marco flexible, disponible para múltiples disposiciones vitales, todas posibles, incluso simultáneas, aún opuestas. Cohabitan así en la CSH\#8 desde un taller de fabricación en serie presidido por la máquina Kazam!, a un gigantesco cuarto de juegos infantil, un ecléctico museo o un rígido salón de té. Un circo de tres pistas donde se dispone hasta el último detalle, donde precisamente los objetos y sus relaciones (físicas, temporales, íntimas, privadas) construyen, juntos, el espacio habitable. Los Eames se trasladan a

17 VENTURI, Robert: Complejidad y contradicción en la arquitectura, editorial Gustavo Gili, Barcelona, $3^{\text {a }}$ ed. 1984 (1966), p. 26 una aún destartalada casa en la Nochebuena de 1949. Rápidamente, antes del mobiliario más básico, aparecen objetos muy personales, habitantes. La costilla de Adán, la Monstera deliciosa que aún hoy, la misma, existe en la casa; el árbol de Navidad; los adornos de papel colgados de las celosías del techo; los cuadros de Hofmann, aún en la pared, antes de su migración al techo; algunos pequeños adornos, juguetes, velas; una silla, concretamente la DCM2 (Dining Chair Metal frame $n^{\circ} 2$ ), una de las three-legged metal rod chair de 1945.

Y aparece el tiempo. Como herramienta de proyecto, como ineludible elemento en este sistema. Y la casa se convierte en sus habitantes. Y Charles Eames, cuyo primer trabajo importante en la academia Cranbrook, donde conocería a Saarinen, y a Ray, había sido una película, aún sin música, sobre la profesora de cerámica Maija Grotell, exhibida en la exposición de la escuela en 1939, y que será determinante para la concepción de aquella organic chair del concurso del MoMA, lo deja pasar...

Cinco años, hasta 1955 en la que la pareja edita el corto (10'40", color) House After Five Years of Living. La película es en realidad una sucesión de imágenes fijas actuando como planos, a veces en planta, otras en alzado e incluso con la ilusión de la sección dada la crudeza de la yuxtaposición material de vidrios, paneles y estructura; también en escorzo general o parcial y sobre todo en detalle; sin embargo tienen apariencia de filmación, por tanto registro literal del transcurso del tiempo, sin serlo. Es posible que sea el paso trémulo del celuloide por los tambores y rodillos del proyector, o quizás la sucesión vibrante de luces y sombras que construye cada escena; el caso es que la ilusión del movimiento, aquella de las fotografías seriadas de Muybridge o de Marey, pero también la del desnu- 
do de Duchamp, que continúa bajando la escalera, está realmente presente. Esta leve distorsión, una película que no es una película, se ve reforzada por la inclusión de la música de Bernstein, que compone una cuidada minisinfonía, un divertimento con flauta, arpa, cello y piano, tocado este último por él mismo, de cuatro movimientos: Setting (54"), Living Room (2'00"), Upstairs (1'45"), Studio (1'45"), entre dos piezas, Prologue and Elements $\left(54^{\prime \prime}\right)$ y Conclusion (1'58"), antes de la pieza final, resumen, Reflections (46"), y nos da las claves para entender este momento final del proyecto Eames. El propio Bernstein escribiría: We wanted the film House and its music to show a warm and loving spirit of place $e^{18}$.

Porque para Charles y Ray Eames la casa está acabada. No aquellas navidades del año 49, no en los planos, ni en la estructura habitada, ni cuando se colocaron las cortinas o las pilonas venecianas encontraron su lugar en la veranda. Ahora, en los cinco años de vida, durante ellos. La casa está acabada y empieza la vida en ella. Y así la casa es siempre igual y diferente. Porque si queremos que todo siga como está, es necesario que todo cambie $^{19}$. El panel ferroboard que separa el estudio del patio intermedio fue azul y después blanco. Las secciones de la fachada pintadas en rojo se han decolorado por efecto del sol, ya no lucen tan rabiosas, y el azul, cerca de la puerta, fue primero azur, después añil, ahora Klein. Los vidrios que se rompieron en los terremotos de febrero de $1971 \mathrm{y}$ octubre de 1987 se repusieron y son otros. Como

18 BERNSTEIN, Elmer: Music for the films of Charles and Ray Eames, Amber Music, New York, 2000. El resaltado aparece en el original.

19 La conocidad cita de El Gatopardo de Lampedusa Se basa en la cita de Jean Baptiste Alphonse Karr plus ça change, plus c'est la même chose (cuanto más cambie, es más de lo mismo), de un artículo de enero de 1849 publicado en la revista satírica Les Guêpes (Las Avispas). algunas baldosas de linóleo. También la lona que sombrea el patio del estudio, aunque es casi idéntica a la colocada en 1950. Las velas se han consumido. Las flores, marchitado, pero hay nuevas velas y nuevas flores. Los árboles tienen ya cien años.

La casa renace de forma continua, suave, ofreciéndonos su propuesta vital y arquitectónica, como el templo de Amaterusa en Ise, destruido y vuelto a construir cada veinte años, si bien Walter Gropius escribió que esto era debido a la necesidad de mantener el estado de perfección constante del edificio por su carácter sagrado, quizás la destrucción del templo de madera, aparejado con cuerdas, sin necesidad de clavos o piezas específicas de unión, se deba a la necesidad de trasmitir el conocimiento material, artesanal, cultural y espacial, la tradición que define a un pueblo, a través del tiempo, siempre igual, cada vez diferente.

Y la peliculita nos muestra la casa, como los planos finales de obra, como las fotografías de Shulman o las visitas guiadas al resto de Case Study Houses. Cada tramo, casi inseparable, del corto va contando la historia de esta nueva arquitectura que se ha separado ya del mito moderno para agarrarse con fuerza a hecho contemporáneo. Fue eso lo que vieron los Smithson, aunque con los ojos tan abiertos, tan sorprendidos, que apenas acertaban a referirse a los detalles, a las flores, a los regalos, a los lazos y los desayunos, después a los juguetes y a las sillas..., hasta rendirse: iLos Eames podían elevar cualquier cosa a la décima potencia! ${ }^{20}$, exclama Alison el día de San Valentín de 1984. Es en Estados Unidos y con los Eames cuando se cierra el

20 SMITHSON, Alison y Peter: Cambiando el arte de habitar, op. cit., p. 91 
período: los años treinta ${ }^{21}$, escriben juntos en The 1930 's. Claro que la casa tiene precedentes, las BAMBOS de Breuer para los jóvenes maestros de la Bauhaus (1926-27), BAMBOS es el acrónimo de sus ocupantes, Breuer, Albers, Meyer, Bayer, Meyer-Ottens y Schmidt, son descritas por el propio Breuer como steel skeleton structure with dry-mounted in-fill panels ${ }^{22}$, a su vez herederas de su primer diseño en Bauhaus, la Kleinmetalhaus de 1925, con cerramiento de paneles metálicos ligeros montados directamente sobre los marcos estructurales de acero, cuyo principio estructural pretende garantizar los siguientes resultados: Una expresión de máxima ligereza. Ni columnas, ni pilares, ni gruesas paredes. Los elementos estructurales que forman los marcos de acero son líneas, cuanto más cerca de la línea absoluta, símbolo inequívoco de lo estático, mejor. Los paneles de cerramiento ya no pertenecen a la familia de los muros pesados -cuanto más próxima esté su materialización del plano absoluto, su praxis simbólica, mejor. La monumentalidad de las masas, un principio arquitectónico mantenido aún hoy en día, es superado por el audaz juego de fuerzas en máxima tensión, por la monumentalidad del intelecto ${ }^{23}$. O Neutra, al ver los planos de la casa Beard, uno dice: la casa de los Eames comienza

21 SMITHSON, Alison: The 1930's, Alexander Verlag, Berlín, 1985

22 BREUER, Marcel: Kleinwohnungen von tip BAMBOS, en Bauhaus, Zeitschrift für Gestaltung, Dessau, 1928, pp. 12-13; citado en VEGESACK, Alexander von y REMMELE, Mathias (editores): Marcel Breuer, Design and Architecture, Vitra Design Museum, Weil am Rhein, 2003, p. 179

23 BREUER, Marcel: Das Kleinmetalhaus Typ 1926, Offset Buch und Werbekunst, n 7, Leipzig, 1926, pp. 371-374. Curisamente la copia de la revista que posee el MoMA en sus archivos, consultada para esta tesis, fue un regalo de Elaine Lustig Cohen a los fondos del museo. La traducción del original es del autor.
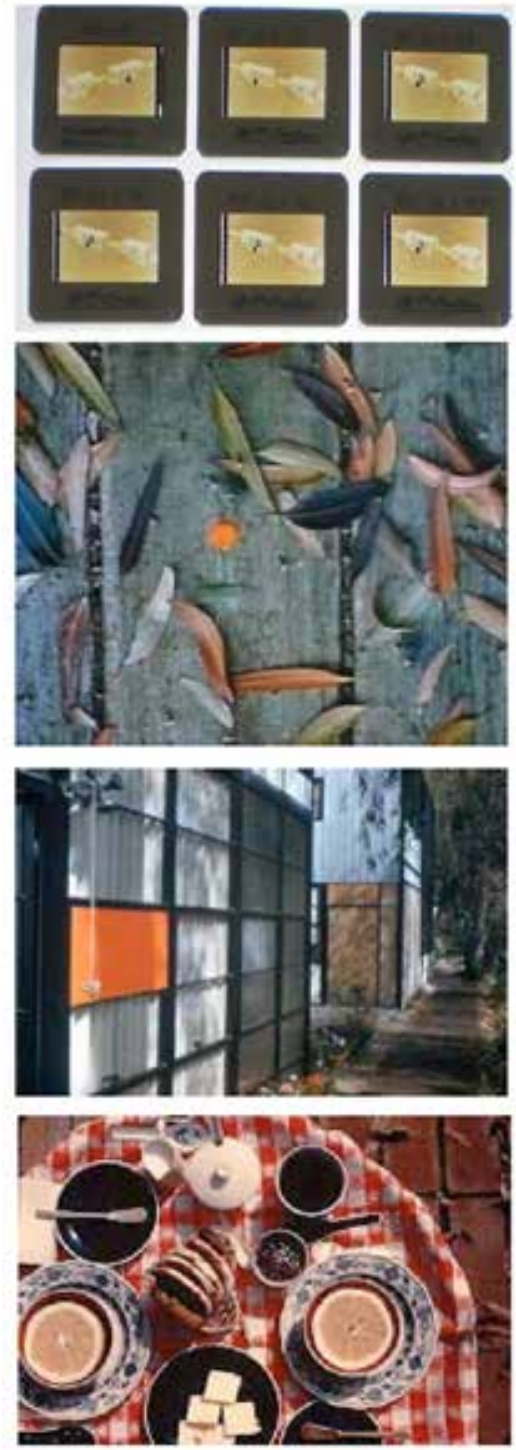

Charles y Ray Eames. CSH\#8. House after five years living.

Eames office, Los Angeles.

$a q u i^{24}$, o... Pero lo esencialmente original, más allá de la idea de Peter Smithson afirmando que

24 SMITHSON, Alison y Peter: Cambiando el arte de habitar, op. cit., p. 92 
la casa de Pacific Palisades, en Estados Unidos y a finales de los cuarenta, cierra un período, los años treinta europeos, es que la casa, realmente, casa y habitantes, abren un nuevo momento en la arquitectura.

Reception in a state of distraction, which is increasing noticeably in all fields of art and is symptomatic of profound changes in apperception, finds in the film its true means of exercise. ${ }^{25}$ (Recepción en un estado de distracción, que está aumentando notablemente en todos los campos del arte y es un síntoma de cambios profundos en la percepción, se encuentra en la película sus verdaderos medios de ejercicio).

La película lo cuenta como los Eames quieren contarlo. Nos permite relajarnos, mirar en ese estado de semidistracción receptiva que explica Benjamin, otra vez esencialmente contemporáneo, como poco antes lo había sido A Communication Primer (1953), lo que hoy se considera la primera presentación multimedia (...) una combianción sinestésica de cine, música, diapositivas, gráficos, aromas y comentarios hablados ${ }^{26}$, y algo más tarde, la proyección múltiple Think en el Pabellón de IBM en la Exposición Universal de Nueva York de 1964. Los nuevos planos son imágenes, la nueva narrativa es la música, las nuevas fotos de espacios prístinos son sustituidas por el espacio ocupado con el fluir de lo

25 BENJAMIN, Walter: The work of art in the age of mechanical reproduction, Prism Key Press, New York, 2012 (primera edición, 1968)

26 FILLER, Martin: La arquitectura moderna y sus creadores. De Frank Lloyd Wright a Frank Gehry, en la traducción de Pablo Sauras, colección Trayectos, Alba Editorial, Madrid, 2007 cotidiano... Taut..., es irrelevante el aspecto de la arquitectura sin gente, lo que importa es el aspecto de la gente en ella. Le Corbusier..., busco con verdadero afán esas casas que son casas de hombres y no casas de arquitectos... Los Eames consiguieron no solo mostrar su casa de forma ineludible como espacio habitado, sino que proyectaron, construyeron y habitaron su casa en un único acto arquitectónico, sensorial y temporal. La materia del espacio se humaniza.

Y así, en el corto, los Elements son la propia casa, el proyecto generado a partir de esa estructura disponible. Pero también son elementos el mar, el prado, los eucaliptos y sobre todo la casa ya construida, los colores, las texturas, los detalles..., y son también elementos el ojo del habitante que hace bello el azar de una hoja sobre el pavimento o una sombra sobre la pared.

La estructura y la piel de los pabellones son una anotación contra la cual se desarrolla un contenido: tanto la vivienda como el contenido se perciben en términos gráficos, un fenómeno estadounidense. $^{27}$

El segundo movimiento, Setting, significa literalmente escenario, seguro que una palabra, por su declinación cinematográfica, muy del gusto de Eames, pero también composición y ajuste, engaste y afilado, arreglo y fraguado, sustantivos con origen en la nominalización de verbos, encierran poderosas acciones relacionadas con el acomodo de dos realidades independientes que una vez engarzadas no se pueden entender como separadas, trascendiendo a sí mismas y construyendo una realidad nueva. Aparecen, indistintamente, imágenes de la casa y el pra-

27 SMITHSON, Alison y Peter: Cambiando el arte de habitar, op. cit., p. 99 
do, de las flores silvestres y las del jardín, de los bordes y los caminos, naturales o construidos, indistintos, en diversos momentos de uso, con y sin hojas, con y sin flores. Pero también el interior visto desde el exterior, muebles, alfombras, objetos cotidianos, establecidos en el lugar (minutos 1:26 a 1:29), así como una mesa, en la veranda, primorosamente compuesta para el desayuno (minutos 1:30 a 1:33). Prado, casa y habitante son juntos.

Un territorio definido por los Eames, determinado por los pabellones colocados en el interior de dicho territorio reforzando la hilera de árboles, junto con, cuando estaba habitado, un contenido Eames $^{28}$.

El resto de secciones, casa, estudio, escaleras... incide en la identificación total entre lugar, espacio y habitante. Las imágenes se suceden equiparadas, democráticas: un único ser múltiple, poliédrico, caleidoscópico, cinematográfico. La reflexión sobre lo natural y lo artificial, su diálogo, en la casa ya habitada, acabada e inacabable se despliega ante nuestros ojos como un mecanismo lúdico y sensual. La casa es una cometa, la casa es un mecano, la casa es un juguete. Los muebles Storage Units con los que tantas veces se la ha comparado son la casa y no al revés. House of Cards es primero House para después ser Cards. Las estructuras de alumnio de las sillas Eames, con asientos intercambiables de madera, de plástico o de piel, explícita la calidad y función de cada uno, pertenecen al usuario y no al edificio (...) ansían moverse en cual-

28 SMITHSON, Alison y Peter: Cambiando el arte de habitar, op. cit., p. 99
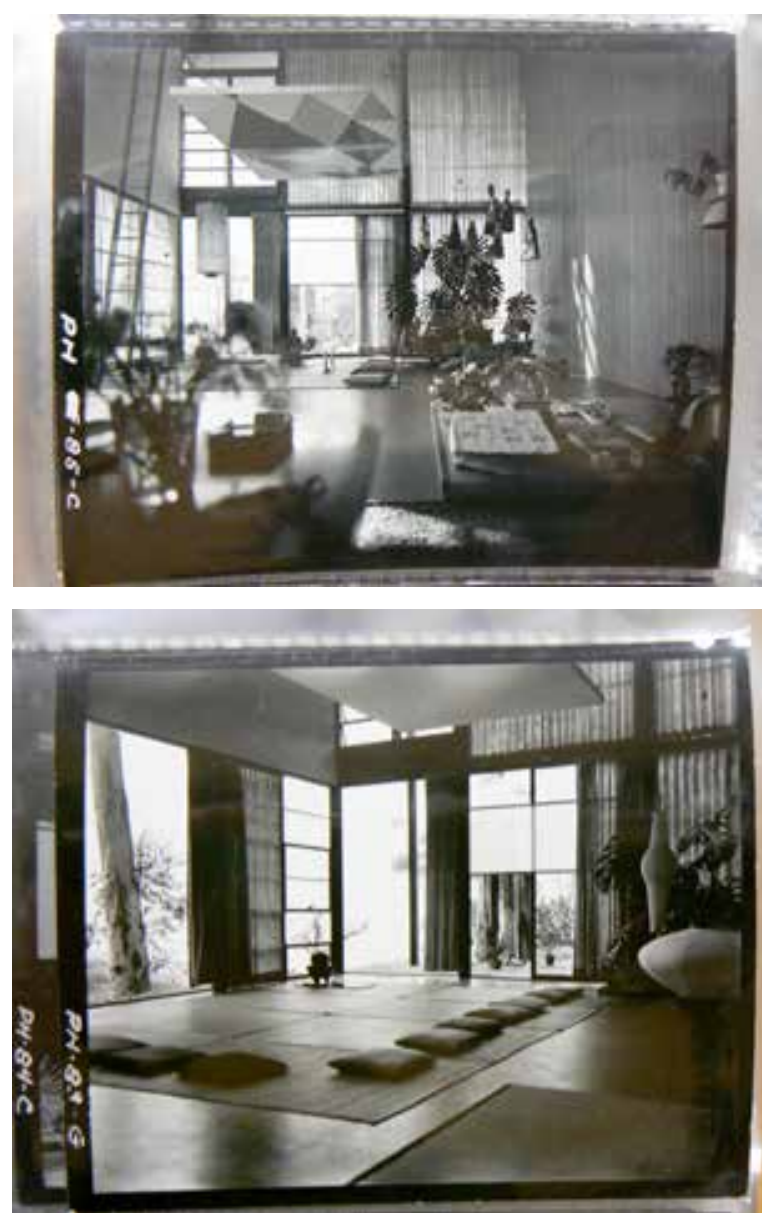

Charles y Ray Eames. CSH\#8. Casa fenomenológica. Eames papers, Library of Congress, Washington.

quier momento ${ }^{29}$, son ligeras, frente a las sillas de Breuer o de Mies, que son de los edificios, pesadas, estáticas, construyendo el espacio de forma rígida y unívoca, moderna.

La casa se aparta también de esa tradición moderna del espacio fluido de Sullivan y

29 SMITHSON, Alison y Peter: Cambiando el arte de habitar, op. cit., p. 93 
Wright, y luego Schindler y Neutra, pero también Mies; contradice la perversión del espacio exterior que la arquitectura de los cincuenta abanderará, y de la que las Case Study Houses son variaciones con repetición de este tema: $e l$ espacio fluido ha dado a entender que se está dentro cuando se está fuera, y que se está fuera cuando se está dentro, en lugar de estar en ambas partes a la vez. Tales manifestaciones de articulación y claridad son extrañas a una arquitectura de complejidad y contradicción que tiende a incluir "lo uno $y$ lo otro" en lugar de excluir "o lo uno o lo otro"30. La casa Eames reconoce sus bordes, sus límites. Pero los espacios interior y exterior no se entienden disociados. Si bien estos límites son muy claros, la fachada múltiple sobre el marco de acero, el muro de hormigón, la plataforma y la cubierta planas, el camino de madera entre la casa y los árboles, y aunque todos aparenten ser muy finos, están construidos para albergar en ellos todo el universo, elevado su espesor a potencias de diez.

Y Reflections es el epílogo de la película de la casa. Le precede un fundido en negro, el único, desde la llama de una vela, tras una sucesión rápida de objetos Eames, frutas, flores, vajilla, colecciones. Si hasta ahora cada pieza de la filmación se había sucedido de forma fluida, los Eames nos permiten un respiro para presentarnos, tras la cesura, en apenas 46 segundos, la casa de verdad.

No sólo el límite entre exterior e interior no se ha disuelto, no sólo sabemos siempre cuándo estamos dentro y cuándo fuera, no sólo los espacios, la arquitectura, contrastan con la naturaleza que ocupa, deliberadamente salva-

30 VENTURI, Robert: Complejidad y contradicción en la arquitectura, Gustavo Gili, Barcelona, 1992 je. Sino que ese límite, aparentemente delgado, finísimo, moderno, cuanto más próxima esté su materialización del plano absoluto, su praxis simbólica, mejor, decía Breuer, no es ya simbólico, ahora es real.

Y esto fue lo que fascinó a los Smithson de los Eames. Lo que hizo construir lujosos umbrales en sus proyectos los cuidados guijarros de bienvenida en Upper Lawn; la escogida piedra fósil, eterna, en los peldaños-estilobato en The Economist; el mágico sendero de Ansty Plum, que hace accesible toda la ladera; la veranda con dos puertas y gato de la Hexenhaus; la penumbra respirable de la Casa del Futuro.

\begin{abstract}
Debemos empezar nuestro pensamiento desde el momento en que el hombre o el niño pisan fuera de su casa (...) tratar de encontrar de qué manera este contacto básico tiene lugar, cuantas casas poner juntas, cuales son las instalaciones que comparten, cuestionando continuamente la arbitrariedad de las soluciones existentes. Este es el principio básico del enfoque ecológico sobre el problema del hábitat. ${ }^{31}$
\end{abstract}

En la Nochebuena de 1949 los Eames entraban por la puerta a su casa. Describe Wilder lo aburrido ver a alguien entrar en una casa por la puerta. Es mucho más interesante cuando alguien entra por la ventana. Pero es esta una puerta nueva, un umbral donde despedirse de la visita, apoyado en su quicio. Una puerta que como la de

31 SMITHSON, Alison \& Peter: The Built World. Urban ReIdentification, Architectural Design 1955, no. 6, Junio, pp. 185-188 
Duchamp en aquel apartamentito de París, su eterna casa (desmontará aquella puerta y la arrastrará con él por medio mundo), una puer- ta que está, a la vez, abierta y cerrada, en una casa, la primera, que alojará para siempre una vida posmoderna.

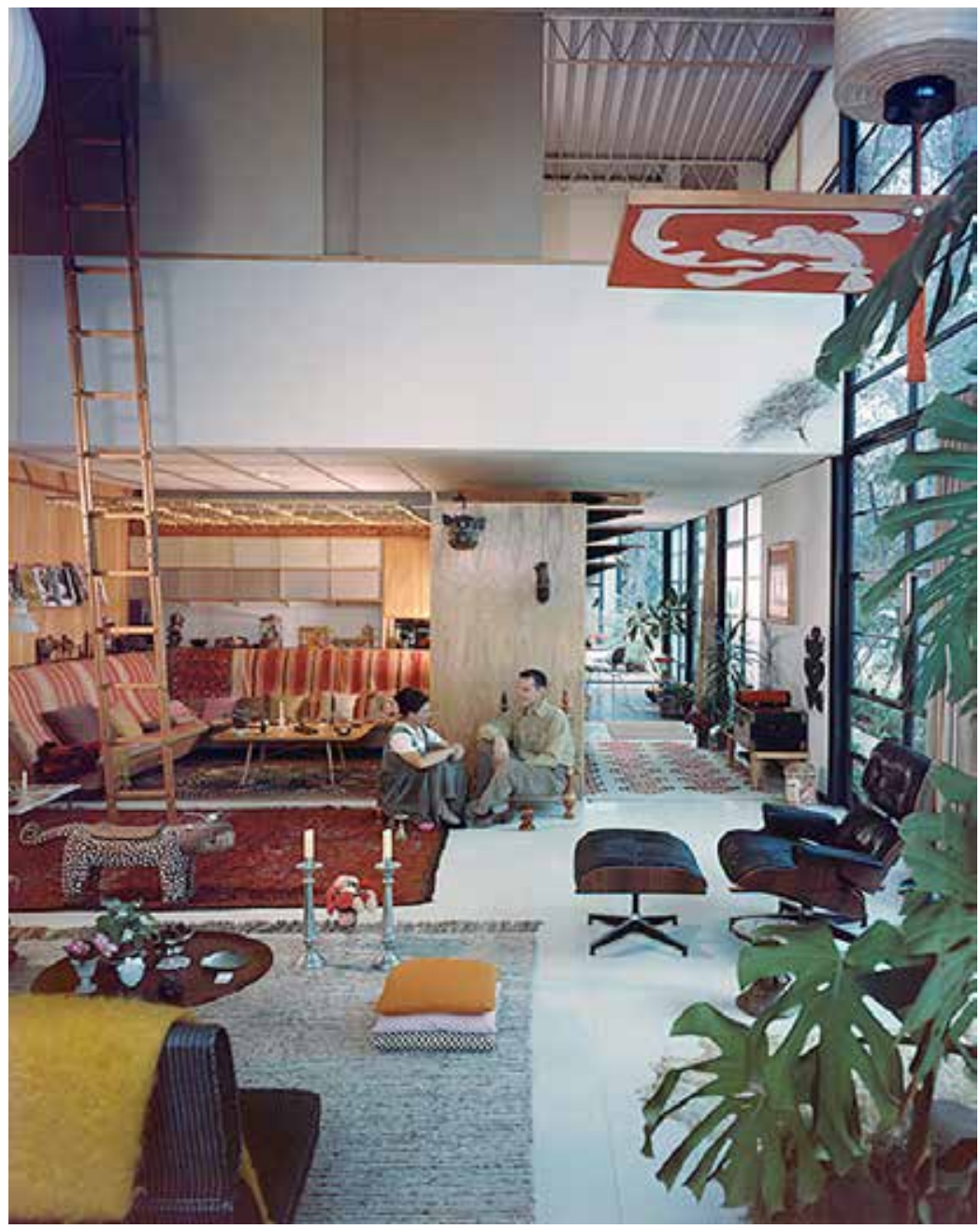

Julius Shulman, Charles y Ray Eames y la casa Eames, 1958. Julius Shulman Photography Archive, Getty Research Institute. 


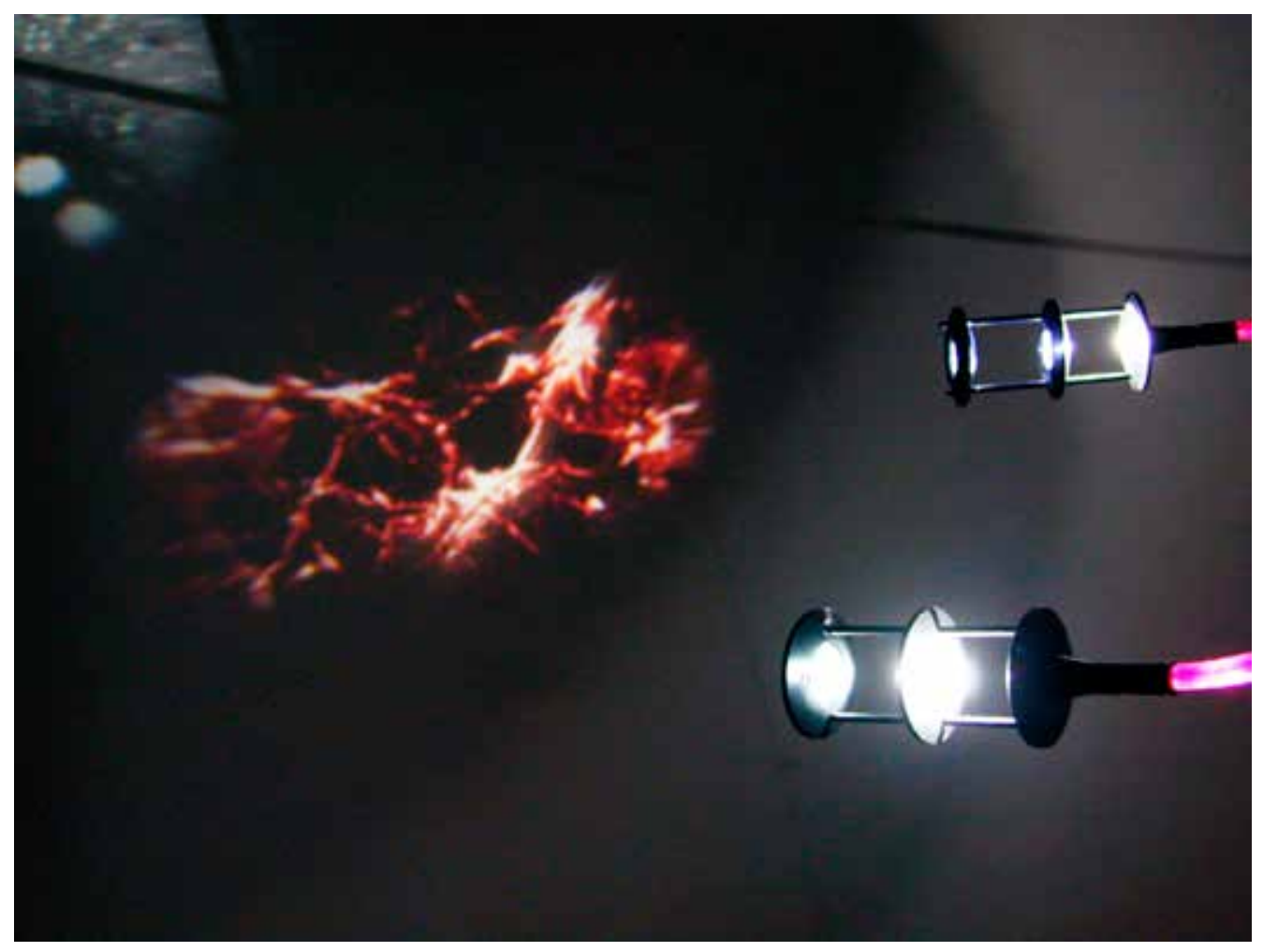

